\title{
Treating gonococcal urethritis in men: Oral amoxycillin potentiated by clavulanate compared with intramuscular procaine penicillin
}

\author{
A S LATIF, J Jithole,* S BVUMBE,* B GUMBO,* M KAWEMBA,† AND \\ R S SUMMERS \\ From the Departments of ${ }^{*}$ Medicine and $\ddagger$ Pharmacy, University of Zimbabwe, and the + City Health \\ Department, Harare, Zimbabwe
}

SUMMARY In a study of 121 men with uncomplicated gonococcal urethritis, 64 were treated orally with a single dose of $3 \mathrm{~g}$ amoxycillin and $250 \mathrm{mg}$ of the specific $\beta$-lactamase inhibitor, clavulanic acid, and 57 with a single intramuscular injection of $2.4 \mathrm{MU}$ procaine penicillin. After seven days, six $(9 \cdot 4 \%)$ patients treated with amoxycillin and clavulanic acid were still culture positive for Neisseria gonorrhoeae, compared with $26 \cdot 3 \%$ of those treated with procaine penicillin.

\section{Introduction}

Gonococcal urethritis is commonly seen in men attending sexually transmitted diseases (STD) clinics in Harare, Zimbabwe. ${ }^{12}$ Routine treatment of gonococcal urethritis at these clinics consists of intramuscular injections of $2.4 \mathrm{MU}$ procaine penicillin given on two occasions, seven days apart. The incidence of penicillinase producing strains of Neisseria gonorrhoeae (PPNG) is, however, increasing, ${ }^{2}$ and large single oral doses of synthetic penicillins with or without probenecid have been effective. ${ }^{3}$ In this trial the efficacy of $3.0 \mathrm{~g}$ of amoxycillin given with $250 \mathrm{mg}$ clavulanic acid ( $\beta$-lactamase inhibitor) was compared with that of $2.4 \mathrm{MU}$ procaine penicillin given intramuscularly as a single dose.

\section{Patients and methods}

STUDY POPULATION

We studied 327 men who voluntarily attended the STD clinic at the medical examination centre in Harare, Zimbabwe. All had urethral discharge and other symptoms of urethritis including dysuria and frequency. Only patients who were culture positive for $\boldsymbol{N}$ gonorrhoeae were included in the study.

\section{CULTURE AND MICROSCOPY}

Urethral smears were stained by Gram's method and examined for the presence of Gram negative intra-

Address for reprints: Dr A S Latif, 14 Viscount Bend, Ridgeview, P O Belvedere, Harare, Zimbabwe

Accepted for publication 2 August 1983 cellular diplococci. Urethral swabs were inoculated onto selective Martin-Lewis medium and incubated at $37^{\circ} \mathrm{C}$ in $10 \%$ carbon dioxide for 48 hours. Colonies of $N$ gonorrhoeae were identified by morphology, Gram staining, oxidase activity, and sugar fermentation. Cultured organisms were tested by the disc sensitivity method for sensitivity to amoxycillin, amoxycillin with clavulanic acid, and minocycline hydrochloride. Organisms were also tested for the production of $\beta$-lactamase by the chromogenic cephalosporin method.

\section{TREATMENT GROUPS}

Amoxycillin $3 \mathrm{~g}$ with $250 \mathrm{mg}$ clavulanic acid was given to 141 men (group A) as a reconstituted suspension of granules in water, while 186 patients (group B) received the standard treatment of $2.4 \mathrm{MU}$ procaine penicillin injected intramuscularly. All patients were instructed not to have sexual intercourse nor to take alcohol or other antibiotics for two weeks.

\section{FOLLOW UP}

Patients were asked to return to the clinic seven and 14 days after treatment. At each follow up visit patients were asked whether they had experienced any side effects from the treatment. Any who had had sexual intercourse in the interim were excluded from the trial.

At each visit, urethral material was inoculated onto Martin-Lewis medium for gonococcal culture and Gram stained urethral smears were examined microscopically. If urethral secretions contained more than four polymorphonuclear leucocytes per 
high power microscopic field and $N$ gonorrhoeae was not isolated at the first follow up visit, postgonococcal urethritis was diagnosed. If, however, eradication of organisms was not achieved, treatment failure was assumed. Treatment failures and patients with postgonococcal urethritis were treated with tetracycline in a dose of $500 \mathrm{mg}$ given orally four times a day for seven days.

STATISTICAL ANALYSIS

The $\chi^{2}$ test was applied to the results.

\section{Results}

Of the 327 patients enrolled into the study, a total of 206 were subsequently excluded, $77(54 \cdot 6 \%)$ from group A and $129(69 \cdot 4 \%)$ from group B. In 51 cases exclusion was due to failure to culture $N$ gonorrhoeae, while $9(2 \cdot 8 \%)$ patients were excluded because reinfection was suspected. The major cause of exclusion was default from follow up. Of the 327 patients enrolled to the trial $146(44 \cdot 6 \%)$ were excluded for this reason, but 64 patients in group A and 57 patients in group B attended for at least one follow up visit and are included in this study. The mean age of patients in group A was 26.5 years (range 20-42) and that of patients in group B was 28. 1 years (range 18-57). A history of at least one episode of gonococcal urethritis was given by 135 $(41 \cdot 5 \%)$ patients in the study.

The table shows the results of urethral cultures for $N$ gonorrhoeae taken seven days after treatment. In group A there were only six failures, giving a success rate of $90.6 \%$, while in group B there were 15 failures, giving a success rate of $73 \cdot 7 \%$. Analysis of these results shows that the difference between the two groups is significant $\left(\chi^{2}=6 \cdot 03 ; p=0 \cdot 01\right)$.

Infections due to penicillinase producing $N$ gonorrhoeae (PPNG) were found in $5(7 \cdot 8 \%)$ patients in group A and $9(15.8 \%)$ patients in group B. Of the 121 patients followed up, infections due to PPNG occurred in $14(11 \cdot 6 \%)$ patients.

Postgonococcal urethritis developed in $5(\mathbf{7 \cdot 8 \%})$ patients who were treated with amoxycillin and

TABLE Treatment results in 121 men with gonococcal urethritis, 64 treated with amoxycillin potentiated by clavulanate (group $A$ ) and 57 with procaine penicillin (group B)

\begin{tabular}{lcccccc}
\hline & $\begin{array}{l}\text { Group } A \\
\text { No (\%) }\end{array}$ & $\begin{array}{l}\text { Group B } \\
\text { No (\%) }\end{array}$ & \multicolumn{2}{c}{$\begin{array}{l}\text { Total } \\
\text { No (\%) }\end{array}$} \\
\hline $\begin{array}{l}\text { Culture negative on day } 7 \\
\text { after treatment }\end{array}$ & 58 & $90 \cdot 6$ & 42 & $73 \cdot 7$ & 100 & 82.6 \\
$\begin{array}{l}\text { Infections due to penicillinase } \\
\text { producing } N \text { gonorrhoeae }\end{array}$ & 5 & $7 \cdot 8$ & 9 & $15 \cdot 8$ & 14 & $11 \cdot 6$ \\
$\begin{array}{c}\text { Patients developing post- } \\
\text { gonococcal urethritis }\end{array}$ & 5 & $7 \cdot 8$ & 8 & 14.0 & 13 & $10 \cdot 7$ \\
\hline
\end{tabular}

clavulanic acid and in $8(14 \cdot 0 \%)$ patients treated with procaine penicillin. This difference was not significant.

No patient complained of side effects with the dosage regimens used.

\section{Discussion}

This study illustrated the problems of medical treatment in developing countries where it is difficult to achieve high or even reasonable follow up rates, whether for further treatment or for evaluation. It is therefore especially important to ensure complete and effective treatment at one visit. In addition, the difficulty of maintaining a sterile environment for parenterally administered drugs means that a single oral treatment is preferable for as wide a range of diseases as possible. It is particularly important to treat diseases occurring most frequently, which include sexually transmitted diseases in general, and gonococcal urethritis in particular, in Zimbabwe. The single oral dose sachet of amoxycillin $3.0 \mathrm{~g}$ and clavulanic acid $250 \mathrm{mg}$ which is reconstituted immediately before administration fulfils these criteria and offers certain advantages, particularly in storage and convenience. The high cure rate we achieved with amoxycillin potentiated by clavulanate confirms the high success rate that has been achieved with this preparation in STD in other parts of the world, ${ }^{4-7}$ and in other diseases. ${ }^{89}$

\section{References}

1. Latif AS. Sexually transmitted disease in clinic patients in Salisbury, Zimbabwe. Br J Vener Dis 1981;57:181-3.

2. Latif AS. Sexually transmitted disease in Harare, Zimbabwe. Southern African Journal of Sexually Transmitted Diseases. 1982; 2:21-3.

3. Mohanty KC, Roy RB. Treatment of uncomplicated gonorrhoea in women with talampicillin in a single oral $1.5 \mathrm{~g}$ dose. Br J Vener Dis 1982; 58: 180-1.

4. Nsanze H, Karasira P, Kabuleeta P, et al. Therapy of genital ulcer diseases: a comparison of amoxycillin alone and amoxycillin combined with clavulanic acid. In: International Symposium on Augmentin, Clavulanate-Potentiated Amoxycillin. Oxford: Excerpta Medica, 1981: 195-203.

5. Kumanoto Y. Basic and clinical studies on BRL 25000 (Augmentin)-Treatment of gonorrhoeal infections. In: International Symposium on Augmentin, Clavulanate-Potentiated Amoxycillin. Oxford: Excerpta Medica, 1981:204-21.

6. Mashimo K. The results of clinical studies with BRL 25000 (Augmentin) in Japan. In: International Symposium on Augmentin, Clavulanate-Potentiated Amoxycillin. Oxford: Excerpta Medica, 1981:227-39.

7. Fast MV, Nsanze H, D'Costa LJ, et al. Treatment of chancroid by clavulanic acid with amoxycillin in patients with $\beta$-lactamase-positive Haemophilus ducreyi infection. Lancel, 1982; ii: 509-11.

8. Levenstein JH, Kritzinger NA. A general practitioner trial of efficacy and tolerability of augmentin in the treatment of common bacterial infections. In: International Symposium on Augmentin Clavulanate-Potentiated Amoxycillin. Oxford: Excerpta Medica, 1981:113-24.

9. Graham VAL, Loes JA, Shaw EJ, Davies RJ. An assessment of the value of augmentin in the management of respiratory tract infections. In: International Symposium on Augmentin, Clavulanate-Potentiated Amoxycillin. Oxford: Excerpta Medica, 1981:138-48. 